\title{
Politização via comunicação organizacional: um estudo de caso sobre o quadro "Solidariedade S.A."1
}

Politicization via organizational communication: a case study on the series "Solidariedade S.A."

Politicación vía comunicación organizacional: estudio de caso sobre la serie "Solidariedade S.A."

\section{Danilo Postinguel}

- Doutor em Comunicação e Práticas de Consumo pela Escola Superior de Propaganda e Marketing (ESPM-SP).

- Mestre em Comunicação e Práticas de Consumo pela ESPM-SP.

- Especialista em marketing pela Pontifícia Universidade Católica de São Paulo (PUC-SP).

- E-mail:d.postinguel@gmail.com 


\section{Resumo}

Neste estudo de caso problematizamos a politização via comunicação organizacional. Para isso, analisamos as 40 primeiras exibições do quadro "Solidariedade S.A.", do telejornal Jornal Nacional, da Rede Globo de Televisão. Partindo de um estado da arte sobre "comunicação organizacional", "politizações" e "engajamentos" que emergem de discursos e de produções audiovisuais e adotando a análise de conteúdo como recurso analítico, observarmos no corpus coletado um movimento de estreitamento entre jornalismo e branding de empresas/marcas engajadas com suas realidades sociais e mercadológicas.

\section{PALAVRAS-CHAVE: POLITIZAÇÃO•COMUNICAC̦ÃO ORGANIZACIONAL・ENGAJAMENTO.}

\section{Abstract}

This paper we study the politicization of organizational communication. We analyzed the first 40 episodes of the serie "Solidariedade S.A." from the news broadcasting Jornal Nacional, from Rede Globo de Televisão. Concept such as "organizational communication", "politicizations" and "engagements" in discourse and audiovisual productions were our theoretical basis and the method of analysis was content analysis as an analytical resource, from the corpus we verified an approximation between journalism and branding of companies/brands engaged with their social and marketing realities.

\section{KEYWORDS: POLITICIZATION・ORGANIZATIONAL COMMUNICATION・ENGAGEMENT.}

\section{Resumen}

En este caso de estudio, problematizamos la politización a través de la comunicación organizacional. Para ello, analizamos los primeros 40 episodios de la serie "Solidariedade S.A." del noticiario televisivo Jornal Nacional, de la Rede Globo de Televisão. Partiendo de un estado del arte sobre "comunicación organizacional", "politizaciones" y "participación" que surgen de discursos y producciones audiovisuales y adoptando el análisis de contenido como recurso analítico, observamos en el corpus un movimiento de estrechamiento entre periodismo y branding de empresas/marcas comprometidas con sus realidades sociales y de marketing. 


\section{INTRODUÇÃO}

A

pandemia de Covid-19 (SARS-CoV-2), decretada oficialmente pela Organização Mundial da Saúde (OMS)², tem sido um grande laboratório do social, principalmente para se estudar como a sociedade e as esferas econômica e política têm enfrentado esse contexto sanitário adverso.

Até mesmo os mais estratégicos estudos situacionais de mercado podem não ter previsto, um ano atrás, mensurar tal impacto nas mais variadas instâncias do cotidiano, obrigando, quase que na ordem mística - a de um passe de mágica -, negócios, marcas, empresas e os mais variados atores sociocapitalistas a repensarem suas lógicas de produção, de consumo e de comunicação. É fato que muitos empreendimentos não conseguiram sobreviver após consideráveis meses - período inicial da quarentena - com suas operações paradas ou funcionando de modo restrito ${ }^{3}$, seja por falta de fluxo de caixa, seja por falta de uma política econômica de acesso ao crédito ${ }^{4}$ para atender o empresariado brasileiro.

Nesse cenário de incertezas, algumas empresas/marcas ganharam visibilidade nos noticiários e nas mídias sociais decorrentes de seus posicionamentos no enfrentamento da crise, ou por meio de discursos e posturas de seus donos/presidentes diante da adversidade. Empresas/marcas como a rede de hamburgueria Madero, a de fast-food Giraffas e a rede de lojas de departamento Havan, figuraram como empresas/marcas que não tiveram tanto êxito durante a pandemia.

A hamburgueria Madero foi alvo de "netativismo" (Di Felice, 2013) e consequentemente de boicotes após a manifestação pública de seu dono contestando o fechamento de estabelecimentos comerciais não-essenciais ${ }^{5}$ em alguns estados e em algumas cidades do país. A onda de revolta foi decorrente de seu discurso, ao enfatizar que "o Brasil não pode parar por conta de '5.000 pessoas ou 7.000 pessoas que vão morrer'”6. Pelas mídias sociais circulava uma espécie de cartaz-paródia (Figura 1), que, a partir da publicidade da marca, subvertia ao acrescentar a mensagem de indiferença à vida humana perante o lucro; uma espécie de estética da resistência via culture jamming (Klein, 2002).

Figura 1: 0 capitalismo não mata

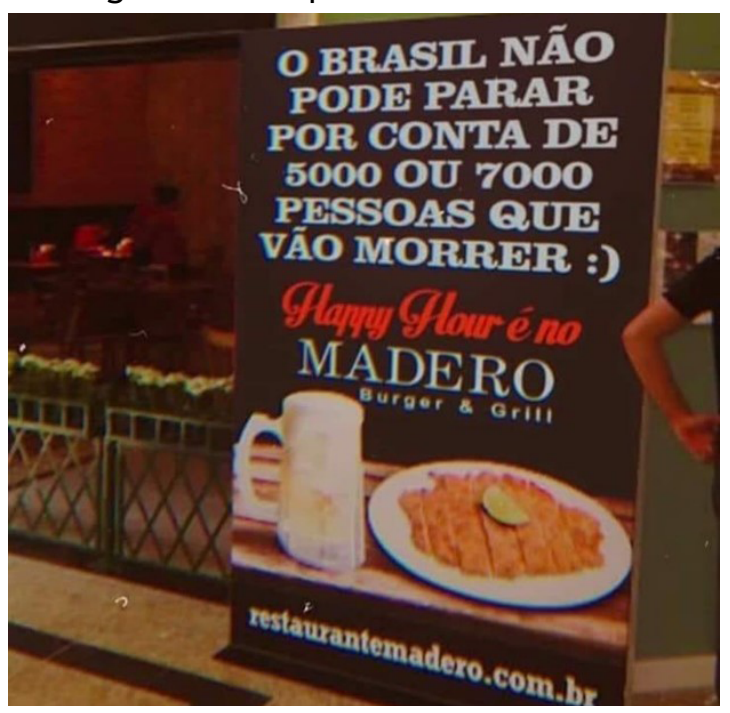

Fonte: Fanpage Comunista Comum ${ }^{7}, 2020$.

2 Disponível em: https://bit.ly/3gLIzPK. Acesso em: 3 ago. 2020.

3 Disponível em: https://glo.bo/3if7wU7. Acesso em: 22 jul. 2020.

4 Disponível em: https://bit.ly/30yRvm4. Acesso em: 22 jul. 2020

5 Disponível em: https://bit.ly/33AvF3w. Acesso em: 22 jul. 2020.

6 Disponível em: https://bit.ly/30vH2rA. Acesso em: 22 jul. 2020.

7 Disponível em: https://bit.ly/2EOWTcf. Acesso em: 22 jul. 2020. 
As outras duas empresas/marcas também fizeram coro ao discurso de salvação da economia e dos postos de trabalho ante as vidas perdidas pelo vírus. A rede de Lojas Havan foi além, e no período de liberação de apenas o comércio essencial no estado de São Paulo, por exemplo, tentou vender produtos da cesta básica, para conseguir, assim, a permanência de funcionamento. Por conta disso, foi barrada pela justiça ${ }^{8}$.

Outras marcas também foram destaque em meio a esse contexto pandêmico, mas em direção oposta, como constatou a pesquisa realizada pela empresa HSR Specialist Researchers e noticiada pelo portal de conteúdos publicitários B9 (Alves, 2020). Segundo o estudo "Marcas Transformadoras", que tinha o "objetivo de identificar as empresas que têm sido mais capazes de construir relevância para o consumidor durante a pandemia de Covid-19", dez empresas/marcas se destacaram, entre elas o Magazine Luiza.

Entre os destaques do Magazine Luiza, por exemplo, estão o apoio e a comunicação direta com a sociedade, como a inclusão gratuita dos pequenos varejistas e autônomos em suas plataformas de e-commerce, com todo o suporte necessário para quem nunca tinha tido um contato tão íntimo com o digital, além das campanhas contra a violência doméstica que protegem a mulher. (Alves, 2020)

As empresas de comunicação também foram impactadas por esse cenário e precisaram repensar seus modelos de negócios, culturas organizacionais e políticas editoriais, como foi o caso da Rede Globo, principal emissora de televisão do país, que mediante o estado de exceção, reeditou seus princípios editoriais, passando a anunciar em seu principal telejornal ${ }^{9}$ Jornal Nacional - as empresas que contribuíram diretamente no combate à pandemia, por meio de ações solidárias.

Toda essa efervescência discursiva de empresas/marcas dos mais variados segmentos de atuação em meio ao contexto da pandemia propiciou a emergência do quadro "Solidariedade S.A." no Jornal Nacional - o objeto de estudo deste artigo. Mais do que uma análise stricto da publicização (Casaqui, 2011) das empresas/marcas envolvidas, ou extenuar o caráter corrosivo do capitalismo-mercadológico travestido de bom-mocismo, interessa-nos observar o imbricamento desses atores sociocapitalistas na dimensão social, da cidadania organizacional e do "engajamento" (Grohmann, 2018) de empresas/marcas por meio da "politização" (Machado, 2011) via comunicação organizacional.

Ademais desta introdução e de seu encerramento, 0 artigo subdivide-se em duas partes. Na primeira, teórica, refletimos sobre o atravessamento da dimensão política nas lógicas de consumo e do reforço de empresas/marcas em visibilizar suas ações engajadas com pautas de interesse coletivo. Na segunda parte, empírica, por sua vez, analisamos o estudo de caso em questão.

\section{UMA NOVA ORDEM POLÍTICA?}

As fronteiras das esferas econômica, social e política estão borradas. Em parte, advento do espraiamento de um ethos do mundo do trabalho que vai se amalgamando à vida social. Essa atual lógica política é estruturada por um sistema capitalistacorporativo e amparado por um sistema midiático, todavia, Sennett (2006, p. 123) vai mais além, nos indagando se "estaria a nova economia gerando uma nova política?".

Não desconsideramos a existência de um sistema produtivo corrosivo, que atenua desigualdades sociais, entretanto, e seguindo pela leitura de alguns pensadores pós-modernos, esse "problema" teria se deslocado dos perímetros industriais

8 Disponível em: https://bit.ly/2PvRhpq. Acesso em: 22 jul. 2020

90 telejornal está no prime time da grade de programação da emissora, ou seja, horário de maior audiência. 
e econômicos, e se encontra, hoje, contaminando as esferas social e cultural (Jameson, 1996). Ou seja, o problema não está mais em apenas questionar os meios de produção, mas de entender as reverberações para o bem e para o mal dessa lógica nos âmbitos social, cultural e midiático.

Ainda no campo das perguntas retóricas um tanto provocativas, Quessada (2003, p.21) nos interpela questionando "de onde se exerce hoje o poder político?". Para a resposta é importante destacar o papel das empresas no sistema econômico e o poder de decisão que migra da cena política clássica (político-partidária) para uma máquina semiótica de expressão capitalista.

Em contextos socioculturais menos desiguais, a participação política de empresas representaria uma ausência do Estado, culminando em um modelo de participação mínima. Contudo, se colocarmos lentes de aumento sobre a realidade brasileira, no que diz respeito ao enfrentamento da pandemia, veremos que esse novo modo de se fazer política é a principal porta de acesso ao social hoje. A asserção encontra respaldo na política regressista do atual governo, de desestímulo e de redução de investimentos nas áreas de saúde, educação, geração de empregos entre outras, além de uma política econômica contida de ajuda ao trabalhador brasileiro e às pequenas e médias empresas durante o momento pandêmico ${ }^{10}$.

“Portanto, o 'menos Estado' desejado pelo [neo]liberalismo não significa um 'menos política'. 0 mercado constitui um modo de organização hoje designado, em nível mundial, como a alternativa política à própria política" (Quessada, 2003, p.29). Nesse atual estágio do capitalismo semiótico (Atem, 2011), principalmente em sociedades e culturas alicerçadas por paradigmas visuais, como em nosso contexto (Rocha, 2008), as produções (audio)visuais têm ocupado um debate central. Sendo assim, problematizar os estímulos audiovisuais recebidos cotidianamente pelas "máquinas de expressão" (Lazzarato, 2006) torna-se lócus para se compreender os agenciamentos e as sensibilidades pertencentes a um tempo presente.

Esse contemporâneo espírito do tempo tem posto em marcha uma expansão afetiva do sistema capitalista. Não mais limitando-se a ofertar novas racionalidades para novos mercados, mas, e principalmente, novas sensibilidades, ou seja, outros modos de se viver. Tendo êxito a empresa/marca que conseguir "colar um significado (afeto mais razão) aos seus significantes (logomarca; cores dominantes; sonoridades; tipologias; gostos; frequência e periodicidade de suas inserções nas mídias, etc.)" (Atem, 2011, p.105).

Esse convite à mobilização e ao engajamento de discussões da agenda sociocultural na comunicação organizacional acontece pois

consumir não se reduz mais a comprar e a "destruir" um serviço ou um produto, como ensina a economia política e sua crítica, mas significa sobretudo pertencer a um mundo, aderir a um universo. E de que mundo se trata? Basta ligar a televisão ou o rádio, fazer um passeio pela cidade, comprar um jornal ou uma revista, para saber que este mundo é constituído pelos agenciamentos de enunciação, pelos regimes de signos em que a expressão constitui uma solicitação. (Lazzarato, 2006, p.100-101)

Ao emitir posicionamentos políticos, as empresas/marcas apresentam-se como "empresas-cidadãs" (Quessada, 2003, p.88). Problematizar uma "empresa/marca-cidadã" a partir dos enunciados, discursos, mensagens, imagens e sons que são materializados por meio de sua comunicação é compreendê-la como engajada em torno de questões que a tocam e/ou tocam a sociedade de consumo em que está circunscrita. É um para além também da "empresa cidadã" que propôs Balonas (2011) ao destacar a ascensão da responsabilidade social na agenda empresarial, favorecendo a emergência do marketing social e, concomitantemente, a de uma publicidade de caráter social. 
Existe um tipo de cidadania aí implicada? Sim, e ela está dentro de um processo de midiatização, de um certo cinismo por parte do consumidor e de uma considerável gramatura plástica e estetizada. É sabido que não se trata de um projeto de Estado, mas sim de um sistema capitalista. No entanto, torna-se paradigmático problematizá-la, afinal, se a crise da democracia também passa pela esfera econômico-mercadológica, precisamos a partir dela encontrar caminhos possíveis de reversão de um empobrecimento do Estado, de uma mão do capital que a tudo e a todos governa e de uma atomização e presentificação por parte dos sujeitos-consumidores nesse atual espírito do tempo.

Em síntese, o atual sistema capitalista-corporativo se alça progressivamente a assumir o campo do político, promovido, principalmente, por mensagens publicitárias. Isso faz com que as empresas/marcas se tornem peças-chave para compreender e potencializar o debate de questões socioculturais que nos tocam.

\section{POLITIZAÇÃO COMUNICACIONAL MERCADOLÓGICA}

Com 0 advento da segunda década do século XXI, potencializou-se "esse processo de politização de práticas corporativas" (Silva; Salgado, 2016, p.59) frente a questões sociais. Não adentrando, inicialmente, no mérito da questão, tanto as que por meio de estratégicas campanhas publicitárias valeram-se da causa como forma de alavancagem de vendas quanto aquelas que se engajaram em torno das mais plurais questões sociais, não podemos desconsiderar a relevância em relação ao fato de que essas campanhas alcançaram "ampla visibilidade e discussão público-midiática" (Silva; Salgado, 2016, p.58).

As provocações que se seguem propõem um pensamento a partir das "politicidades via audiovisual". Politicidade que não apenas emerge da cena política clássica, como nos lembra Rocha (2008). Os desafios que se desvelam da reflexão incutem para nós a compreensão do papel e a centralidade do audiovisual. E em nossa particular investigação, o espraiamento da "comunicação organizacional" (Kunsch, 2006) como protagonista em prol de uma mobilização social de questões pertinentes ao nosso contexto sociocultural.

Entre os principais protagonistas dessa virada no parafuso afetivo-audiovisual estão campanhas publicitárias organizacionais de infindáveis empresas/marcas. Ecoam principalmente pelas "mídias com funções pós-massivas" (Lemos, 2007), exemplos de campanhas que, com certo tom celebrativo por parte da crítica especializada, abraçam causas sociais, lançam reflexões e promovem discussões de inúmeras questões cristalizadas nos mais plurais contextos socioculturais.

Longe de uma reflexão apocalíptica ou integrada, queremos, nessa linha tênue entre uma crítica radical e um total deslumbre, "repensar novas formas de ativismo que não passam pelas formais relações com o Estado" (Machado, 2011, p.11). Novas configurações de engajamentos, que, inclusive, estão além dos coletivos e movimentos organizados dae pela sociedade civil.

Problematizar essas contemporâneas formas de mobilizações, inclusive as capitaneadas por atores mercadológicos, seriam os indicativos possíveis para se radiografar "uma nova atmosfera no estágio avançado da sociedade de consumo" (Machado, 2011, p.12). Estágio entrecruzado pelas comunicações mercadológica e institucional e o consumo responsável/ politizado. Pensamos, aqui, uma politização do consumo gestado por estratégias midiáticas para serem consumidas nos contextos de recepção em que circulam.

A gênese para pensarmos essa proposta em torno de uma mobilização de empresas/marcas estaria nas primeiras discussões de responsabilidade social corporativa, que ainda são "um forte movimento de autorregulamentação dos mercados [...], no sentido de cumprir metas e critérios exigidos por instituições detentoras dos selos de sustentabilidade e engajamento 
social" (Machado, 2011, p.145). Todavia, pensar em um engajamento de empresa/marca é ultrapassar campanhas publicitárias com verniz político apenas para a construção de bom-mocismo de imagem de marca perante o mercado e a sociedade.

Advogamos que o exercício do engajamento e posterior articulação com os debates de cidadania foram interpretados a partir de outros referenciais, além dos modelos tradicionais de ocupação e reivindicação dos espaços público-coletivos. Diferentemente dos modelos clássicos com sua crítica à ausência de projetos coletivos, essas novas formas de engajamentos, via politização comunicacional, são construídas a partir de convocações individuais tanto para o consumo quanto para a ação.

\section{ESTUDO DE CASO: METODOLOGIA E ANÁLISE}

Adotamos para esta pesquisa de natureza qualitativa, o método investigativo do "estudo de caso" (Yin, 2010), a partir do quadro "Solidariedade S.A.", do telejornal Jornal Nacional. Entendemos que o quadro, em seu respectivo telejornal e posterior emissora de televisão, realizou um feito paradigmático ao relacionar a triangulação: telejornalismo, cobertura da pandemia e veiculação de empresas/marcas. Um acontecimento até então improvável para a TV Globo por conta de seus princípios editorais, que proibiam a veiculação de empresas/marcas em seus telejornais de modo promocional.

0 quadro "Solidariedade S.A." teve sua primeira exibição em 14 de abril de 2020. Exceto no primeiro dia que, além da explicação do quadro, apresentou um roll de empresas/marcas e seus respectivos projetos e ações solidárias de enfretamento à pandemia. Nos demais dias e subsequentes ao da estreia, o quadro durava, em média, dois minutos, contendo, além da apresentação das empresas/marcas e suas ações, discursos de seus porta-vozes que buscavam articular os valores organizacionais às ações realizadas.

Referente ao quadro, no dia de sua estreia, a jornalista Renata Vasconcelos, uma das apresentadoras do telejornal, enfatizou que:

A pandemia do coronavírus provocou uma infinidade de ações solidárias no Brasil: de cidadãos e de empresas. Os exemplos de cidadãos solidários você vê quase todo o dia por aqui, com nome e sobrenome. Já as iniciativas das empresas, a gente tem apresentado como sempre fez: sem mencionar as marcas delas. Mas a partir de hoje, e enquanto durar a pandemia, o Jornal Nacional vai mudar isso, porque pra superar um desafio tão grande é importante mostrar o que muitas e muitas empresas e empresários têm feito nesse período. Você vai conhecer agora algumas dessas iniciativas. (Jornal Nacional, 2020)

0 material coletado obedeceu ao seguinte protocolo de coleta: foram analisadas as quarenta primeiras exibições, compreendidas entre o período entre 14 de abril e 29 de maio de 2020". 0 critério de constituição do corpus deu-se pelo fato de as primeiras quarenta exibições ocorrerem em todas as edições do telejornal do período, após essa data, o quadro passou a ser intercalado, ou seja, sendo exibido um dia sim e no outro não.

Não tivemos conhecimento acerca dos critérios de seleção das empresas que figuraram no quadro, também não foi possível atestar se a TV Globo monetizou o espaço do quadro para veicular e realizar inserções de empresas/marcas em detrimento de outras, assim como questionou o teólogo e filósofo Leonardo Boff em seu perfil no Twitter (Figura 2), ou se realmente foi uma atitude de reconhecimento da solidariedade das empresas no período da pandemia. Todavia, não desconsideramos os interesses, acordose tratados mercadológicos por trás das escolhas. Também não levamos em consideração para esta análise os montantes doados, mas sim a visibilidade das empresas/marcas e suas articulações ao universo da politização via comunicação organizacional.

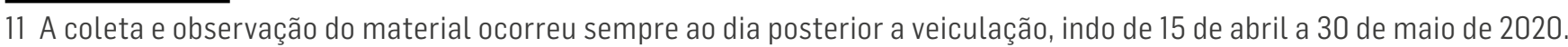


Figura 2: Critério de seleção das empresas

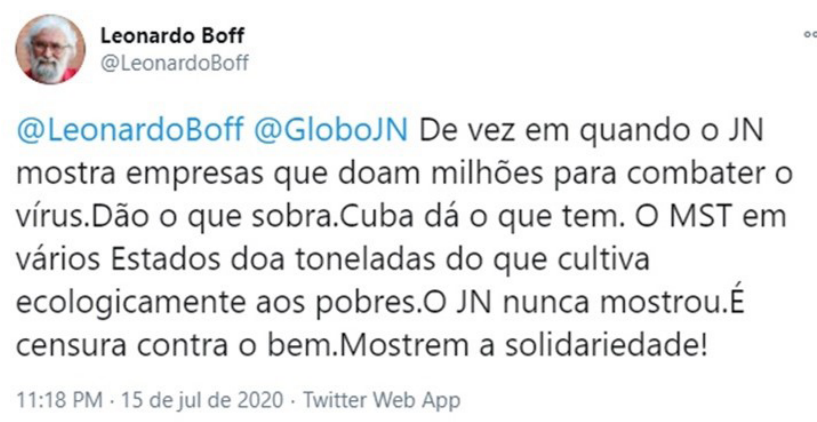

Fonte: Twitter'12, 2020.

No quadro a seguir apresentamos todas as empresas/marcas que figuraram durante o período de coleta do corpus. Ressaltando que as empresas/marcas visibilizadas no quadro foram as que tiveram porta-vozes discursando sobre e a partir delas, afinal existiram subempresas e submarcas, ou associações que representaram algumas empresas/marcas do segmento, todavia foram apresentadas de forma secundária, apenas como ilustração para orientar o telespectador de qual grupo a empresa do dia visibilizada pertencia.

Quadro 1: Veiculação das empresas/marcas durante o período de coleta

\begin{tabular}{|c|c|}
\hline DIA & EMPRESAIMARCA \\
\hline \multirow{6}{*}{1} & Itaú Unibanco (e parceiros) \\
\hline & Rede D'or (e parceiros) \\
\hline & BRF Alimentos \\
\hline & Fundação Bando do Brasil \\
\hline & Ifood \\
\hline & Lojas Americanas \\
\hline \multirow{3}{*}{2} & NuBank \\
\hline & Magazine Luiza \\
\hline & Braskem \\
\hline \multirow{2}{*}{3} & XP Inc. \\
\hline & Ambev \\
\hline \multirow{2}{*}{4} & Natura \& Co América Latina \\
\hline & Instituto Votorantim \\
\hline \multirow{2}{*}{5} & Vale \\
\hline & COSAN \\
\hline \multirow{2}{*}{6} & BR Distribuidora \\
\hline & Suzano \\
\hline \multirow{2}{*}{7} & Embraer \\
\hline & Deloitte Brasil \\
\hline \multirow{2}{*}{8} & BTG Pactual \\
\hline & L'oréal Brasil \\
\hline \multirow{2}{*}{9} & Gerday \\
\hline & Grupo Boticário \\
\hline \multirow{2}{*}{10} & Nestlé no Brasil \\
\hline & Stone Pagamentos \\
\hline \multirow{2}{*}{11} & Distribuidora Ipiranga \\
\hline & Softys Brasil \\
\hline \multirow{2}{*}{12} & Banco Safra \\
\hline & Instituto Aço Brasil \\
\hline
\end{tabular}

\begin{tabular}{|c|c|}
\hline DIA & EMPRESAIMARCA \\
\hline \multirow{2}{*}{13} & Carrefour Brasil \\
\hline & EDP \\
\hline \multirow{2}{*}{14} & Klabin \\
\hline & ArcelorMittal Aços Longos \\
\hline \multirow{2}{*}{15} & Mapfre Fundación \\
\hline & Hydro \\
\hline \multirow{2}{*}{16} & Sesi e Senai SP \\
\hline & Allianz Seguros \\
\hline \multirow[b]{2}{*}{17} & Coca-Cola Brasil \\
\hline & IBP \\
\hline & \\
\hline \multirow{2}{*}{18} & Norte Energia \\
\hline & Unitedhealth Group Brasil \\
\hline \multirow{2}{*}{19} & Câmara de Com. Árabe-Brasileira \\
\hline & Accenture no Brasil \\
\hline \multirow{2}{*}{20} & Caoa Chery \\
\hline & Ypê \\
\hline \multirow{2}{*}{21} & Conf. Nacional das Indústrias \\
\hline & Unilever Brasil \\
\hline \multirow{2}{*}{22} & Usina Itaipu Bi-Nacional \\
\hline & Grupo Heineken \\
\hline \multirow{2}{*}{23} & Associação Brasileira do Aluminio \\
\hline & Nivea \\
\hline \multirow{2}{*}{24} & Marfrig Global Food \\
\hline & Danone Brasil \\
\hline \multirow{2}{*}{25} & PepsiCo no Brasil \\
\hline & Petrobras \\
\hline \multirow{2}{*}{26} & Fiat Chrysler no Brasil \\
\hline & Grupo Bayer no Brasil \\
\hline
\end{tabular}

\begin{tabular}{|c|c|}
\hline DIA & EMPRESAIMARCA \\
\hline \multirow{2}{*}{27} & Samsung América Latina \\
\hline & Kraft Heinz \\
\hline \multirow{2}{*}{28} & Lojas Renner S.A. \\
\hline & Minerva Foods \\
\hline \multirow{2}{*}{29} & P\&G Brasil \\
\hline & Qualicorp \\
\hline \multirow{2}{*}{30} & Via Varejo \\
\hline & Uber no Brasil \\
\hline \multirow[b]{2}{*}{31} & 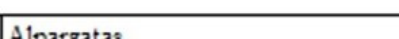 \\
\hline & I aboratório Aché \\
\hline & \\
\hline \multirow{2}{*}{32} & Johnson \& Johnson Brasil \\
\hline & Peninsula Participações \\
\hline \multirow{2}{*}{33} & JBS \\
\hline & RaiaDrogasil \\
\hline \multirow{2}{*}{34} & Grupo Solvi \\
\hline & Iguatemi Emp. de Shopping Centers \\
\hline \multirow{2}{*}{35} & Grupo Uol PagSeguro \\
\hline & Grupo Zurich Seguros no Brasil \\
\hline \multirow{2}{*}{36} & Mondelez Brasil \\
\hline & Copel \\
\hline \multirow{2}{*}{37} & 99 \\
\hline & Anglo American no Brasil \\
\hline \multirow{2}{*}{38} & Hidrovias do Brasil \\
\hline & Banco BMG \\
\hline \multirow{2}{*}{39} & Ass. Bra. da Ind. Têxtil e Confecção \\
\hline & Enel Brasil \\
\hline \multirow{2}{*}{40} & EcoRodovias \\
\hline & Amazon Brasil \\
\hline
\end{tabular}

Fonte: Elaborado pelos autores, 2020. 
Outro ponto importante referente às análises das empresas/marcas do nosso objeto é que elas se restringiram aos perímetros comunicacionais do quadro. Mesmo entendendo a importância de reflexões e possíveis incoerências entre "o que elas dizem" (comunicação organizacional) e "o que praticam" (cultura organizacional) (Kunsch, 2006), privilegiamos a potencialidade de engajamento dessa comunicação de empresas/marcas em causas sociais de interesse público.

A asserção se aplica às empresas/marcas iFood, aplicativo de deliveryde refeições, que figurou na inauguração do quadro, doando um montante destinado ao auxílio dos restaurantes parceiros e aos entregadores que viessem a contrair o vírus, e à Uber (no trigésimo dia do corpus), outra empresa de aplicativos de transporte privado, que criou um fundo para atender motoristas e entregadores do aplicativo em todo o país que também viessem a parar de trabalhar por recomendação médica. Contudo, meses depois, iFood e Uber foram duas das empresas/marcas envolvidas na "greve dos entregadores de aplicativos", ou naquilo que ficou conhecido como o "\#BrequeDosApps", quando entregadores paralisaram as entregas de deliverys, exigindo melhores condições de trabalho e contestando as arbitrariedades dos aplicativos ${ }^{13}$.

Como método de análise, optamos pela "análise de conteúdo" (Bardin, 2011), obedecendo seus três polos cronológicos: a) a pré-análise e a b) exploração do material, que, a partir de uma leitura flutuante, nos propiciou enquanto unidades de contexto de codificação para a descrição analítica do corpus coletado: o "exercício da cidadania organizacional", o "papel das organizações frente ao atual contexto social, político e sanitário" e "a politização emergente da comunicação organizacional", para, enfim, realizarmos o último polo cronológico, que é c) o tratamento dos resultados, a inferência e a interpretação.

Na dimensão discursiva, por diversas vezes foi reiterada, pelos porta-vozes das empresas/marcas, a asserção de que 0 engajamento em ações solidárias visava o "exercício de cidadania organizacional" (primeira unidade de contexto). Ilustramos com o excerto do diretor-geral da Klabin e porta-voz no quadro, Cristiano Teixeira, veiculado no décimo quarto dia de observação 14: "[...] A gente acredita que numa postura de empresa-cidadã, estar próximo dessas comunidades e atuar naquilo que elas precisam, é essencial para a visão de longo prazo dessa companhia".

Reaparecendo, a presente asserção, em outros dois momentos do corpus, no décimo oitavo dia de coleta dos dados ${ }^{15}$, por meio do porta-voz no quadro e CEO do UHG Brasil, José Carlos Magalhães, ao articular a realização de ações solidárias ao exercício da cidadania e da solidariedade: "Isso é uma questão de solidariedade, isso é uma questão de cidadania [...]". E no vigésimo quinto dia de observação ${ }^{16}$, por intermédio do presidente da Petrobras e representante da empresa no quadro, Roberto Castello Branco, ressaltando ser o momento de as empresas exercerem o exercício da cidadania corporativa: "É hora de exercer a cidadania corporativa. Todos nós temos que nos unir, a Petrobras e empresas privadas, para mitigar o impacto dessa crise sobre o nosso país".

Localizamos no corpusum residual articulando as ações solidárias das empresas à responsabilidade social. Mesmo sinalizado por Machado (2011), ser essa uma discussão inaugural para o atual estágio das politizações via comunicação e consumo, muitos dos porta-vozes no quadro articularam em seu discurso a associação de ações de enfrentamento à pandemia ao compromisso de responsabilidade social; para a pesquisa, uma estratégia retórica sedimentada na comunicação organizacional. Ilustramos com discursos que vão desde uma aproximação mais ampla e genérica, como na fala do porta-voz e presidente da Deloitte Brasil, Altair Rossato, localizada no sétimo dia de coleta ${ }^{17}$ : "A gente entende que isso não é um ajuda, é uma responsabilidade [...]".

\footnotetext{
13 Disponível em: https://bit.ly/2PxjRqE. Acesso em: 29 jul. 2020.

14 Disponível em: https://globoplay.globo.com/v/8519941/. Exibição em: 29 abr. 2020.

15 Disponível em: https://globoplay.globo.com/v/8530902/. Exibição em: 4 maio 2020.

16 Disponível em: https://globoplay.globo.com/v/8549549/. Exibição em: 12 maio 2020.

17 Disponível em: https://globoplay.globo.com/v/8499716/. Exibição em: 21 abr. 2020.
} 
Até as aproximações mais objetivas, como a que ocorreu por intermédio de Fabio Schettino, porta-voz no quadro e presidente da Hidrovias do Brasil, no trigésimo oitavo dia do $\operatorname{corpus}^{18}$, discursando a favor de uma política de responsabilidade social: "A empresa se sente na obrigação social de fazer. Nós estamos aí, nesses municípios que têm carências e a empresa tem uma política de responsabilidade social muito séria e entende que esse é o momento que a empresa tem que dar a contrapartida nas regiões onde atua".

No que compete às outras duas unidades de contexto, o "papel das organizações frente ao atual contexto social, político e sanitário" e a "politização emergente da comunicação organizacional", percebemos certa convergência entre elas, a partir do que os porta-vozes reportaram no quadro. Por exemplo, no discurso do vice-presidente de relações institucionais do Carrefour Brasil, e porta-voz no quadro, exibido no décimo terceiro dia de coleta ${ }^{19}$; Stéphane Engelhard enfatiza que ao estar envolvida com essas ações a empresa/marca cumpre com o seu papel social: "[...] Como que nós poderíamos ajudar e quem ajudar? Então na verdade começamos a elaborar uma campanha de doação e isso é a nossa contribuição. Como ajudar quem precisa mais? Então, para nós, a gente está preenchendo totalmente o nosso papel social". Outra empresa/marca que também reforçou esse deslocamento de uma atuação estrita do setor econômico para também o setor social foi a Fiat Chrysler, por meio de seu presidente Antonio Filosa, no vigésimo sexto dia do corpus ${ }^{20}$, destacando que: "[...] Acho que, dessa forma, as empresas fazem jus ao que elas são na natureza, ou seja, elas são razões sociais. Então, além de ser atores econômicos e industriais, nós temos responsabilidade com a sociedade".

Abordando especificamente a unidade de contexto "politização emergente da comunicação organizacional", destacamos que não existiram falas de críticas direcionadas às gestões públicas das três esferas do executivo, justificável, até mesmo, pelo produto comunicacional em que o discurso era veiculado. Entretanto, a ideia de superação das fronteiras entre o público e o privado esteve presente; a constatação dialoga com a ideia de uma lógica empresarial que também passa a administrar o universo sociopolítico (Lazzarato, 2006; Quessada, 2003; Sennett, 2006).

Essa ideia esteve presente nos discursos de Marcelo Arantes de Carvalho, vice-presidente de pessoas e desenvolvimento sustentável da Braskem e porta-voz no quadro no segundo dia de exibições²1: "Não existe agora o momento do público e do privado". Por vezes, travestido de um discurso que reivindica o trabalho em rede, como sugeriram o CEO da Natura \& Co. para América Latina, João Paulo Ferreira: "Um problema tão complexo como esse que estamos vivendo, jamais poderá ser solucionado por um único ente, por um único indivíduo, uma única empresa. A solução vem da colaboração; da colaboração em rede [...]" (quarto dia de observação ${ }^{22}$ ). Em consonância com o discurso do presidente da Coca-Cola Brasil, Henrique Braun, destacando no décimo sétimo de coleta dos dados ${ }^{23}$, que: "A gente acredita que a saída para um cenário tão complexo, quanto estamos vivendo hoje, passa necessariamente por uma atuação em rede onde todos colaboram [...]". Para além do sinalizado pelos porta-vozes, suas falas nos provocam a pensar não apenas na relação entre o público e privado, mas, e a partir desse contexto de exceção e isolamento social, pensar "do público para as redes", como sugere Di Felice (2008); enquanto desdobramentos do protagonismo e cooperação de empresas/marcas junto a essa cena que ascende digito-socio-política.

Também pudemos observar esse engajamento/posicionamento por parte de algumas empresas/marcas para dimensões que ultrapassam o universo do consumo e do mercadológico. A primeira empresa/marca que associamos a tal pensamento

\footnotetext{
18 Disponível em: https://globoplay.globo.com/v/8584768/. Exibição em: 27 maio 2020.

19 Disponível em: https://globoplay.globo.com/v/8517008/. Exibição em: 28 abr. 2020.

20 Disponível em: https://globoplay.globo.com/v/8552131/. Exibição em: 13 maio 2020.

21 Disponível em: https://globoplay.globo.com/v/8485593/. Exibição em: 15 abr. 2020.

22 Disponível em: https://globoplay.globo.com/v/8491400/. Exibição em: 17 abr. 2020.

23 Disponível em: https://globoplay.globo.com/v/8527753/. Exibição em: 2 maio 2020.
} 
é a EDP, ao articular o envolvimento de questões além das econômicas aos valores organizacionais. Para Miguel Setas, presidente da EDP e porta-voz no quadro: "Essa missão solidária, acho que é uma missão que tem que juntar toda a sociedade, juntar todo mundo. E por isso EDP está verdadeiramente está engajada de participar de uma forma muito ativa [...]” (décimo terceiro dia de observação). E de forma mais contundente, observamos no discurso do porta-voz e presidente da Via Varejo, Roberto Fulcherberguer, esse chamamento à politização de práticas organizacionais: "O grande legado, pra mim, que fica de toda essa crise, é o legado da iniciativa privada, de fato, entender o seu papel e ajudar a sociedade mais carente do Brasil" (trigésimo dia do corpus ${ }^{24}$ ).

\section{CONSIDERAÇÕES FINAIS}

Neste artigo observamos, a partir do quadro "Solidariedade S.A.", o engajamento de empresas/marcas a partir de ações sociais e midiáticas à emergência de uma politização via comunicação organizacional. Grohmann (2018), ao problematizar, a partir de um estado da arte, os sentidos da noção de engajamento para a pesquisa em comunicação, e mesmo direcionando as discussões para o plano dos estudos de recepção, nos possibilitou pinçar nas entrelinhas de sua reflexão o questionamento do papel das empresas/marcas nesse cenário de engajamento para além de versões maniqueístas e/ou reiteração de teorias funcionalistas acerca da publicização de empresas/marcas com vistas para o engajamento de consumidores exclusivas ao consumo de produtos e serviços.

Em um diálogo um tanto antagônico, pensamos, articulados ao pensamento de Kotler, Kartajaya e Setiawan (2017), que a mobilização de empresas/marcas a um posicionamento e responsabilização de demandas sociais, políticas e culturais, tem emergido daquilo que os autores definem enquanto "marketing 4.0", em "que o marketing deve adaptar-se à natureza mutável dos percursos do consumidor da economia digital", guiando-nos "na sua viagem desde a atenção até à advocacia" (p.20). Todavia, tendo como pano de fundo e já considerado por muitos consumidores como um dever organizacional, a versão anterior - o "marketing 3.0" -, ou seja, um marketing centrado no humano, no social. Aparecendo por vezes nos discursos dos porta-vozes das empresas/marcas quando as associavam à responsabilidade social e a seu caráter humano.

Essas empresas/marcas dialogam com o espírito do tempo e com consumidores que anseiam "por signos dados pelas [empresas]/marcas que o ajudem a se posicionar moralmente e não financeiramente" (Brandini, 2017, p.284) em seu círculo de interação e socialização. Implicando em uma comunhão com empresas/marcas que problematizam problemas sociais, e preferivelmente dialoguem com as de seus consumidores, por intermédio de ações e estratégias comunicacionais, nesse levante de apresentá-las enquanto politizadas com as pautas em que atuam (Postinguel, 2019). Sendo sabido que esse chamamento a um engajamento e politização via o universo do consumo reverbera em resultados e ganhos de retornos de imagem e identidade corporativa (Kunsch, 2006), além de identificação.

São outros modos de se publicizar (Casaqui, 2011), via comunicação organizacional, em mídias com funções massivas (Lemos, 2007). Enquanto muitas e atuais pesquisas se voltam às análises desses discursos e produções audiovisuais politizadas de organizações em mídias com funções pós-massivas, o presente objeto - quadro "Solidariedade S.A." do telejornal de maior audiência do país de TV aberta -mostra-se um fenômeno analógico importante, ao trazer notoriedade tanto para a comunicação de massa quanto para os discursos organizacionais. Afinal, esse engajamento comunicacional corporativo "aparece como ativo simbólico com valor econômico na esfera das trocas comerciais globais" (Michetti, 2017, p.120-121), como, também, "é operada como uma espécie de lastro simbólico que legitima a conversão de capital econômico em capital e poder políticos".

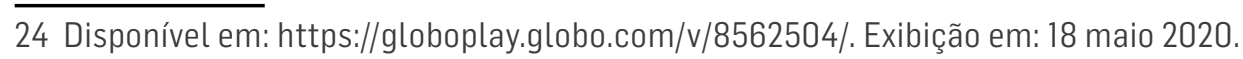


Por fim, cabe enquanto investigação futura aprofundar as análises, percebendo recorrências e/ou continuidades desse "brand journalism"25 (Araújo, 2019), ou seja, desse estreitamente entre o jornalismo e o branding, para verificar se a atual política editorial da Rede Globo de Televisão foi apenas uma exceção, ou se os modelos de jornalismo cada vez mais se aproximarão de diálogos com o mercado e o universo da sociedade de consumo.

\section{REFERÊNCIAS}

ALVES, Soraia. Pesquisa coloca Magazine Luiza, Netflix e iFood como marcas transformadoras durante a pandemia. $B 9$, São Paulo, 2020. Disponível em: https://bit.ly/30wEU2J. Acesso em: 22 jul. 2020.

ARAÚJO, Marcelo Marques. Brand journalism: a comunicação empresarial em interface com jornalismo, publicidade e relações públicas. In: CONGRESSO BRASILEIRO DE CIÊNCIAS DA COMUNICAÇÃO, 42., 2019. Anais [...]. Belém: UFPA, 2019. Disponível em: https://bit.ly/2DFscpo. Acesso em: 14 jul. 2020.

ATEM, Guilherme Nery. A lógica social da forma-consumo. Alceu, Rio de Janeiro, v.12, n.23, p.100-111, 2011.

BARDIN, Laurence. Análise de conteúdo. São Paulo: Edições 70, 2011.

BALONAS, Sara. Publicidade sem códigos de barras: contributos para o conhecimento da publicidade a favor de causas sociais em Portugal. Braga: Húmus, 2011.

BRANDINI, Valéria. 0 consumo de causas sociais na era da midiatização digital. Ação Midiática, Curitiba, n.14, p.275-289, 2017.

CASAQUI, Vander. Por uma teoria da publicização: transformações no processo publicitário. Significação, São Paulo, v.38, n.36, p.131-151, 2011.

DI FELICE, Massimo. Do público para as redes: a comunicação digital e as novas formas de participação social. São Caetano do Sul: Difusão, 2008.

DI FELICE, Massimo. Ser redes: o formismo digital dos movimentos net-ativistas. MATRIZes, São Paulo, v.7, n.2, p.49-71, 2013.

GROHMANN, Rafael. A noção de engajamento: sentidos e armadilhas para a pesquisa em comunicação. Famecos, Porto Alegre, v.25, n.3, p.1-17, 2018.

JAMESON, Fredric. Pós-modernismo: a lógica cultural do capitalismo tardio. São Paulo: Ática, 1996.

JORNAL NACIONAL. Solidariedade S.A. Rede Globo, Brasil, 2020. Disponível em: https://globoplay.globo.com/v/8482558/. Acesso em: 14 abr. 2020.

KLEIN, Naomi. Sem logo: a tirania das marcas em um planeta vendido. 2.ed. Rio de Janeiro: Record, 2002.

250 jornalismo é fundamental para a construção de conteúdos relevantes a partir da relevância de marcas. Para isso, os critérios de noticiabilidade, precisão, certitude, investigação, fontes, abrangência, utilidade pública entre outros, não se perdem quando há um projeto de branded content, ao contrário, a comunicação multipotencial possibilita um grande avanço na interface branding e jornalismo (Araújo, 2019, p.15). 
KOTLER, Philip; KARTAJAYA, Hermawan; SETIAWAN, Iwan. Marketing 4.0: mudança do tradicional para o digital. Coimbra: Actual, 2017.

KUNSCH, Margarida M. Krohling. Comunicação organizacional: conceitos e dimensões dos estudos e das práticas In: MARCHIORI, Marlene (org.). Faces da cultura e da comunicação organizacional. São Caetano do Sul: Difusão, 2006. p.167-190.

LAZZARATO, Maurizio. As revoluções do capitalismo. Rio de Janeiro: Civilização Brasileira, 2006.

LEMOS, André. Cidade e mobilidade: telefones celulares, funções pós-massivas e territórios informacionais. MATRIZes, São Paulo, v.1, n.1, p.121-137, 2007.

MACHADO, Mônica. Consumo e politização: discursos publicitários e novos engajamentos juvenis. Rio de Janeiro: Mauad X, 2011.

MICHETTI, Miqueli. 0 discurso da diversidade no universo corporativo: "institutos" empresariais de cultura e a conversão de capital econômico em poder político. Contemporânea, São Carlos, v.7, n.1, p.119-146, 2017.

POSTINGUEL, Danilo. Masculinidades plurais, ativismos de marcas e ativismos de consumidores-fãs-fiscais. 2019. Tese (Doutorado em Comunicação e Práticas de Consumo) - Escola Superior de Propaganda e Marketing, São Paulo, 2019.

QUESSADA, Dominique. O poder da publicidade na sociedade consumida pelas marcas. como a globalização impõe produtos, sonhos e ilusões. São Paulo: Futura, 2003.

ROCHA, Rose de Melo. Comunicação e consumo: por uma leitura política dos modos de consumir. In: BACCEGA, Maria Aparecida (org.). Comunicação e culturas do consumo. São Paulo: Atlas, 2008.

SENNETT, Richard. A cultura do novo capitalismo. Rio de Janeiro: Record, 2006.

SILVA, Terezinha; SALGADO, Tiago Barcelos Pereira. Controvérsias em torno dos "Casais" de 0 Boticário: 0 acontecimento e a afetação dos públicos. Verso e Reverso, São Leopoldo, v.30, n.73, p.58-69, 2016.

YIN, Robert K. Estudo de caso: planejamento e métodos. 4. ed. Porto Alegre: Bookman, 2010.

Artigo recebido em 07.08.2020 e aprovado em 14.04.2021. 